\title{
CLINICAL AND PATHOLOGICAL STUDY OF THEILERIOSIS IN CATTLE AND BUFFALOES IN AL-GHANIEM REGION, ASSIUT GOVERNORATE, UPPER-EGYPT
}

\author{
AHMED M.A. ZAITOUN ${ }^{1}$; AHMED ABDEL-RADY ${ }^{1}$; AMIRA ALHOUSARY ${ }^{1}$ and \\ MICHEAL R.A. MAXIMOUS ${ }^{2}$ \\ ${ }^{1}$ Infectious Diseases, Dept. Animal Med., Faculty of Vet. Med. Assiut Univ. \\ ${ }^{2}$ Vet. Directorate of Assiut Governorate \\ This article is an abstracted form of the Master Vet Thesis in Infectious Diseases, Edited by the fourth author $(* *)$ under \\ supervision of the first three authors $(*)$
}

Received: 22 August 2019; Accepted: 29 September 2019

\begin{abstract}
A detailed Clinico-pathological profile of clinically diseased cattle and buffaloes with Theileriosis located in AlGhaniem region, Assiut Governorate, was aimed. Theileria annulata was confirmed by the presence of T. annulata piroplasms in blood smears and/or lymph smears followed by polymerase chain reaction (PCR). During the period of investigation (April 2015 to August 2018), out of the clinically inspected cattle $(n=300)$ and buffaloes $(\mathrm{n}=100), 80(26.67 \%)$ and $15(15 \%)$ cases were clinically suspected to have Theileriosis, respectively. The positive cases were molecularly identified (PCR). The general observed signs were anorexia, fever, swelling of superficial lymph nodes. Ocular lesions were white cloudiness were more obvious in the center of cornea rather than the borders (yellowish colored corneoscleral opacity surrounded by hyperemic band). A watery discharge from the eyes. Serous ocular discharge (watery lacrimation) was remarkable, however in severe cases the ocular discharges was accumulated in the medial canthus. Some newly born calves of less than one month exposed to ocular symptoms mainly protruding of eye ball with ictric conjunctiva. The clinical examination of conjunctivae of the clinically suspected cases with Theileriosis indicated that icteric appearance of conjunctivae in some cases. Three cases showed petechiated conjunctivae. In our study some animals showed up--word visible bulging of temporal fossa. Visible protrusion of hemorrhagic conjunctiva with apparently exophthalmia (ocular edema) were observed. Bloody diarrhea and tarry like diarrhea, change in feeding behavior or habit like depraved appetite by eating mud, soil were noticed. On the other side, the most prominent necropsy features the recently succumbed animals: Gross changes in various organs including heart lungs, trachea, stomach, liver, spleen, kidneys superficial lymph nodes, mesenteric lymph nodes, small and large intestine. All mucous membranes and conjunctivae, peritoneum and abdominal fatty tissues were icteric. On external observation. Jaundice, petechial hemorrhages involving mucosal and serosal surfaces of many organs as well as body fat. In the thoracic cavity, the most prominent autopsy findings were obviously extra edematous swelling of all lobes of the lung, hydrothorax and the lung was distended, discolored, solid in texture, and filled with exudate by palpation, The liver was friable, yellowish, and larger than normal, with the gall bladder being markedly distended with dark olive-green or brownish green bile. The abomasum was the most severely affected organ in the alimentary canal, it contains numerous ulcers about $3 \mathrm{~mm}$. in diameter .a few linear ulcers were present on the leaves. There were prominent hemorrhagic ulcers and petechial hemorrhages were seen in the abomasum of the most cases. There were remarkable enlargement of spleen (splenomegaly) were also recorded. The kidneys were congested or dark brown in color and their perirenal fat were yellowish in color. The heart had petechial and hemorrhages on the outer and inner surface of the auricles.
\end{abstract}

Key word: Cattle, Buffaloes, Theileriosis, polymerase chain reaction, autopsy finding

\section{INTRODUCTION}

Explanation of the severity of symptoms and lesions of theileriosis in nature from mild to severe started by (Mehlhorn et al., 1994). Gill et al. (1977) indicated that the clinical signs and severity of

Corresponding author: Dr. Micheal R.A. Maximous

E-mail address: michealraoof@yahoo.com

Present address: Vet. Directorate of Assiut Governorate theileriosis depend on pathogenicity of the strain of Theileria, the quantum of infection and the susceptibility and age of the host The work described here was a part of a study undertaken to determine the incidence, distribution, epizootiology and pathogenicity of tropical theileriosis in Al-Ghaniem region-Assiut Governorate, Egypt. The present investigation was conducted to study Clinical and necropsy findings of Theileria infection in Cattle and 
Buffaloes in Al-Ghaniem region, Assiut Governorate, Egypt.

Cattle and buffaloes play a pivotal role in Egyptian's economy by uplifting the socioeconomic condition of resource-poor farming communities and alleviating poverty. They are the principal animals for milk and meat production in Egyptian land. Theileriosis is an outstanding endemic vector-borne hemoprotozoal disease of ruminants particularly cattle and buffaloes caused commonly by two hemo-protozoal agents, Theileria parva and Theileria annulata. (Kundave et al., 2017). Theileria annulata infection appears to be more prominent in large ruminant population in tropical, subtropical, and Mediterranean including southern Europe and Middle East countries; from Morocco, Algeria to India and China, causes Bovine Tropical Theileriosis (BTT). Such distribution may be attributed to the distribution of suitable tick vector (Neitz., 1959; Flach and Ouheli., 1992, Tuli et al., 2015, Gharbi et al., 2017). Tropical theileriosis imposed serious constraints on the health and productivity of the infected animals and the economic impacts of the disease in both cattle and buffaloes population and there are enormously reviewers reviewed that tropical theileriosis acts as a terrifying enemy for the productive capacities and reproductive performance of beef and dairy cattle and buffaloes , and it causes morbidity and mortality in calves and non- indigenous (exotic) cattle rather than native (local) breed. (Kivaria et al., 2007, Gharbi and Darghouth, 2015 and Gharbi et al., 2017). Moreover control of theileriosis is costly precious and the highest outcome is mostly associated with the intensive tick control rather than the diagnostic procedures and therapy of the infected animals (Decastro et al., 1997). Seriously, it is matter of common fact that following recovery from primary Theileria annulata infection, the infected animals become persistent carriers (latent form of bovine theileriosis) and act as reservoirs of infection . Thereby, playing a critical role in disease epidemiology (Gharbi et al., 2017). Practically, diagnosis of Tropical Theileriosis in large and small ruminants is primarily based on Giemsa -stained blood smear in association with detection of schizonts in Giemsa -stained smears from lymph node fine needle aspiration, which is a fast and low cost tool, but it is not suitable for epidemiological studies because of its low sensitivity (Uilenberg 2004). Moreover, by microscopic examination, it is difficult to discriminate different species of Theileria that may occur either as a single or mixed form within the same bovine host (OIE, 2014). On the other side, serodiagnosis was also utilized (Bilgic et al., 2016). The serological tests are also not suitable due to cross - reactivity with other Theileria species (Dolan 1986). Inability to distinguish between active cases and animals with antibodies due to prior infection (Roy et al., 2000). To overcome the above mentioned difficulties in laboratory diagnosis of Theileria infection, Ilhan et al. (1998), Roy et al. (2000) and Sahoo et al. (2017) corroborated that the polymerase chain reaction (PCR) method allows the detection of a single piroplasm in extra little amount of blood sample.

\section{MATERIALS AND METHODS}

\section{Area}

The current study was undertaken in Al-Ghaniem region- Assiut Governorate, Egypt. Al-Ghaniem is one of the big centers of Assiut Governorate about 40 kilometers away from Assiut city. It is considered as a desert rural city and It is divided into an agricultural part and consists of the eastern half. The second half is desert,. It also divided into four areas, northwest, southwest, northeast and southeast that include different villages like Dir Elganadla, Almashayaa, Ghaniem Bahary, Ghaniem Sharq and Ghaniem qibly. The above mentioned villages are the biggest villages of Al- Ghaniem center.

\begin{abstract}
Animals
During the period of investigation (April 2015 to August 2018), a total number of randomly selected 300 cattle were clinically inspected. Out of the 300 cattle, 80 cattle (Bos Taurus) were clinically suspected. These animals were hematologically examined, A total number of 100 Buffloes were clinically inspected .Out of them 15 Buffaloes (Bubalus bubalis) were clinically suspected and were hematologically examined. The clinically examined animals were in different ages and sexes. All the animals were randomly collected from different villages in Al-Ghaniem extreme south-west of Assiut Governorate.
\end{abstract}

\section{Parasitological study}

Blood samples were collected from the ear veins in vacutainers containing EDTA for the preparation of thin blood smears. Kelly (1979) and (Chaudhri and Gupta, 2003). All smears were then fixed with absolute methanol, stained with Giemsa, and examined by light microscopy at $\times 1,000$ under oil immersion for the presence of Theileria $\mathrm{sp}$. piroplasms. Blood samples were also processed for DNA extraction. Lymph node biopsy smears from the enlarged lymph nodes were collected or carried out by using 18 gauaze needle air dried which rapidly inserted into the substance of swollen lymph node (usually pre scapular) the hub of the needle then covered with a finger and the needle withdrawn. (Van Amstel, 1982).

\section{Clinical and necropsy examinations}

A thorough clinical examination was performed on all animals (Jackson G.G. Peter. \& Peter D. Cockcroft, 2002). The signs in clinical cases of $T$. annulata infection were observed and recorded. Thin blood smears were also prepared from the ear veins of all animals. Lymph node aspirates were prepared from 
suspected cases of tropical theileriosis Kelly (1979). Animals which died from infection (six) were examined post-mortem. Six animals (four females and two males) were recently succumbed subjected to postmortem examination according to Jubb et al. (1993).

\section{DNA extraction and PCR assay}

This test is designed to include the examination of $20 \%$ of clinically suspected cases of cattle $(n=16)$ and $50 \%$ of clinically suspected buffaloes $(n=7)$, so large ruminant tested by PCR were 20 samples. Out of 20 tested samples $10(50 \%)$ tested by Theileria spp primer and all $20(100 \%)$ tested by $T$. annulata primer according to D'oliveira et al. (1995). and concerning small ruminants. By amplification of Theileria spp. DNA from blood sample were extracted and obtained from both clinically suspected and infected animal and then tested by using PCR technique depending on two types of primers as shown in table (1). The first was derived from the gene encoding the SSU r RNA gene used to diagnose Theileria spp. The second primer was derived from the gene encoding the $30-\mathrm{kDa}$ major Theileria annulata merozoite surface antigen according to D'oliveira et al. (1995).

Table 1: Primers sets used in PCR according to D"oliveira et al. 1995.

\begin{tabular}{|c|c|c|c|}
\hline Primer & Sequence & Product & Pharacteristic \\
\hline Forwared & GTAACCTTTAAAAACGT & 721 & T.annulata annulata \\
Reserve & GTTACGAACATGGGTTT & & \\
\hline Forwared & AGTTTCTGACCTATCAG & & Theileria \\
\hline
\end{tabular}

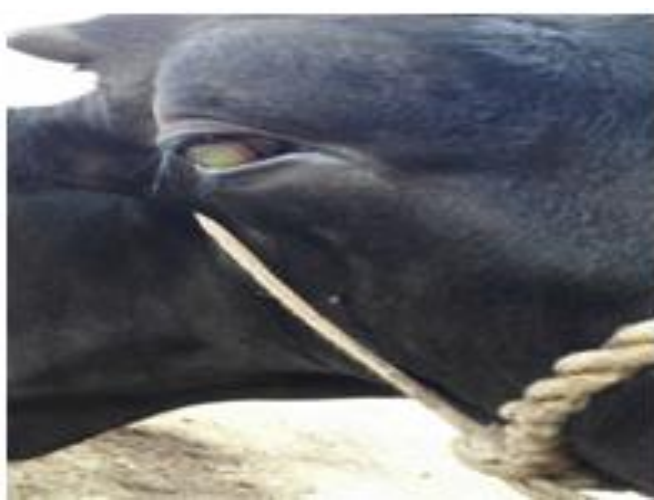

Fig.1: Yellowish corneo-scleral opacity surrounded by hypermic zone in cattle

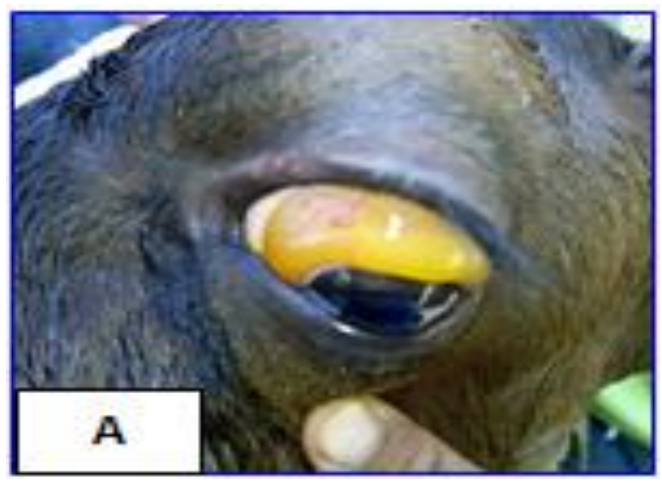

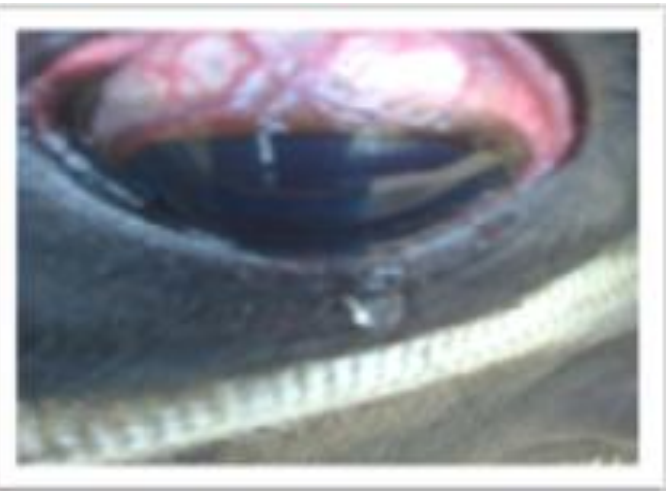

Fig.2: Severly congested eye with lacrimation

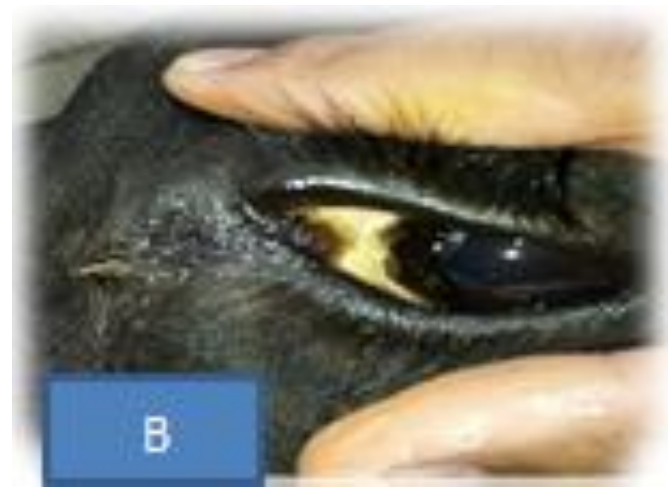

Fig.3: Eye lesion of animals infected with Theileria annulata (icteric condition sugessting hepatic insufficency) A; Ocular lesion of eye of unweaned cattle acalf with exophthalmia and petechae (highly degree of icteric conjunctiva) .......B; adult cattle with icteric mucous membrane of eye. 


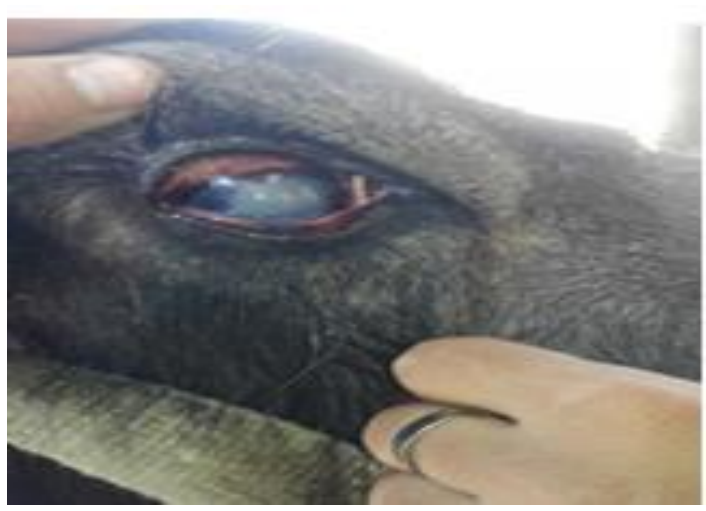

Fig.4: Severly congested buffalo eye with lacrimation

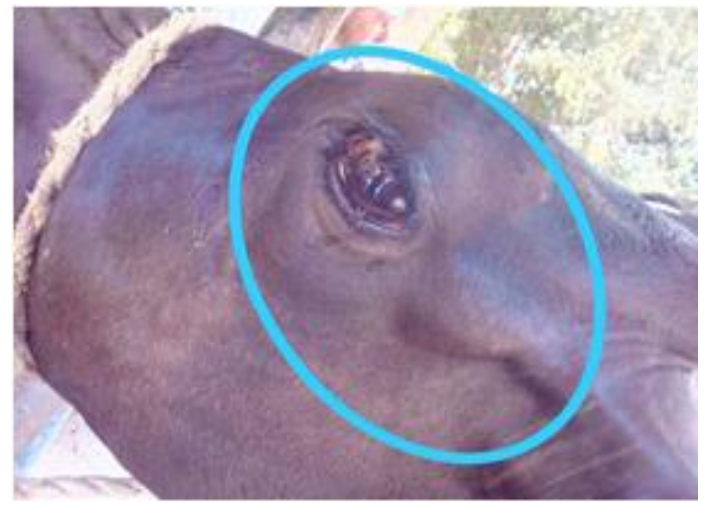

Fig.6: Out-bulging (edemtous swelling) of infra orbital fossa

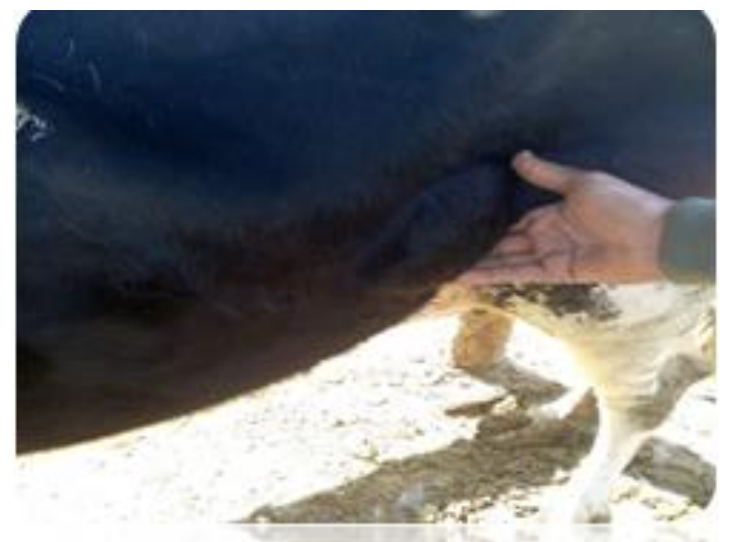

Fig.8: Prefemoral lymph node enlargement (cattle)

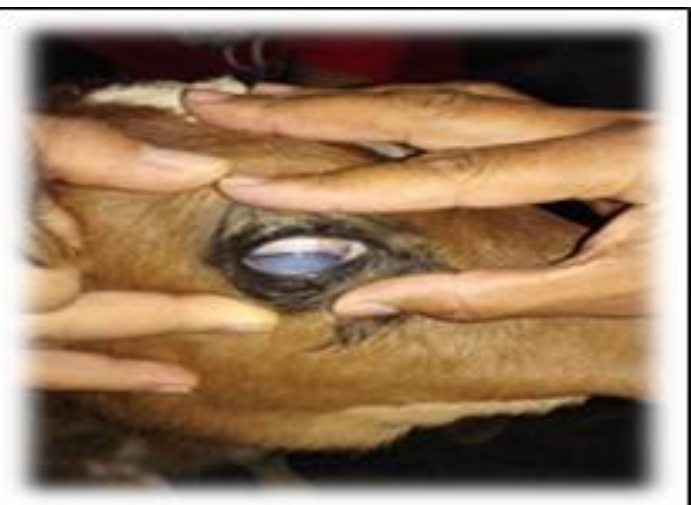

Fig.5: Corneal opacity of young unweaned cattle calf

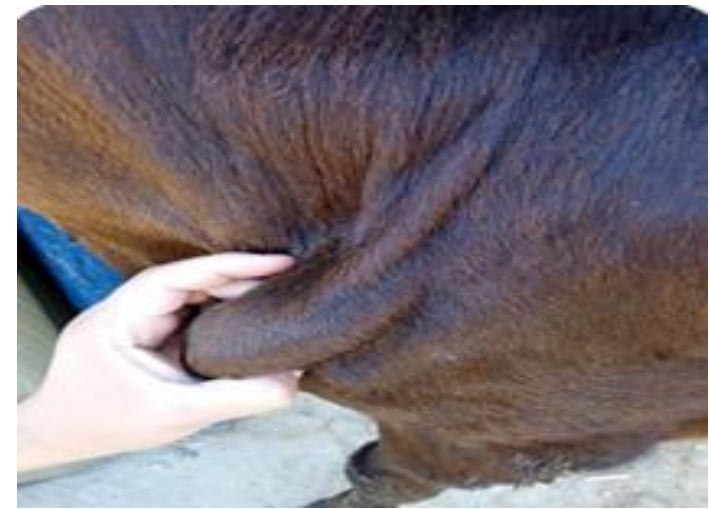

Fig.7: Prescapular lymph node enlargement in young cattle calve 3 month

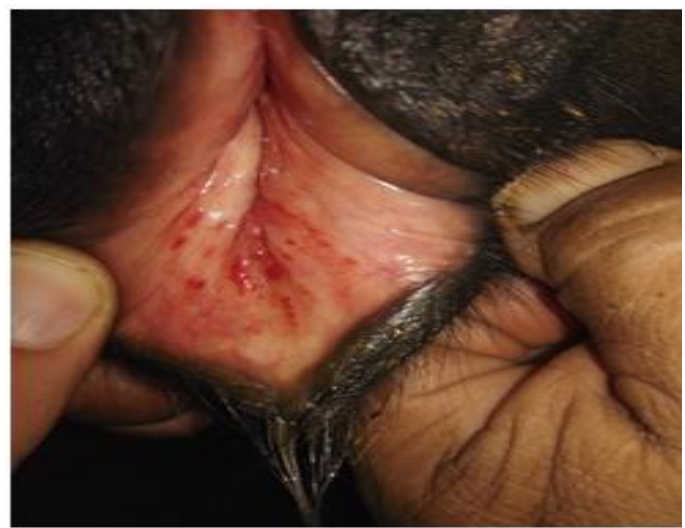

Fig.9: Petechiae of vulvar mucous membrane

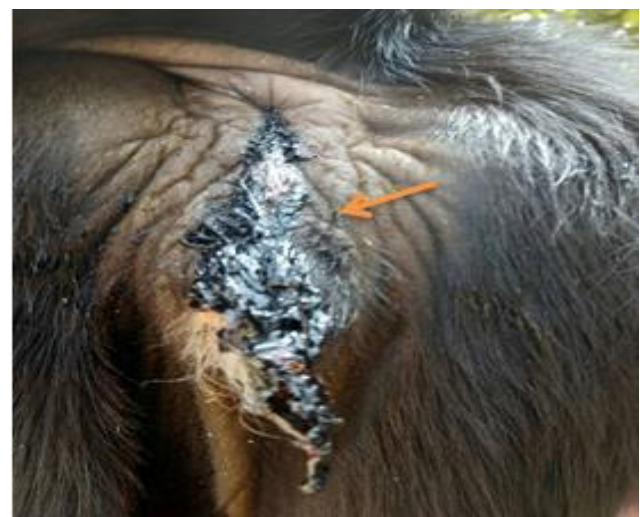

Fig. 10 Tarry feces of clinically confirmed case of Theileria annulata. 

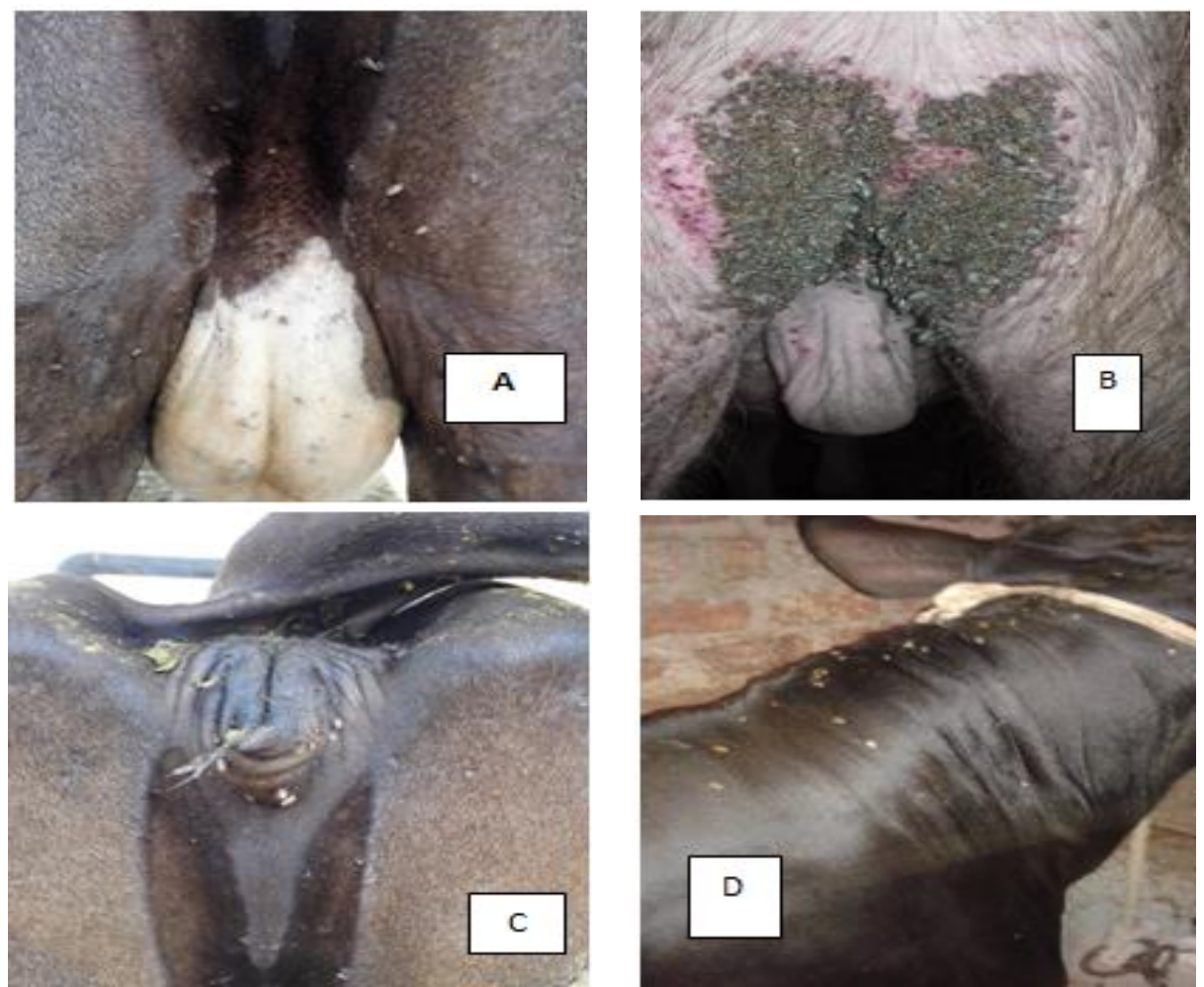

Fig.11: Tick infestation in cattle and buffaloes at different body parts.

A, tick infestion in inner side of the thigh in cattle

$B$, highly infested male buffalo ox at perineum region.

$C$, presence of the tick under tail and vulva at cattle

$D$, presence of tick on weather and neck region at male cattle.
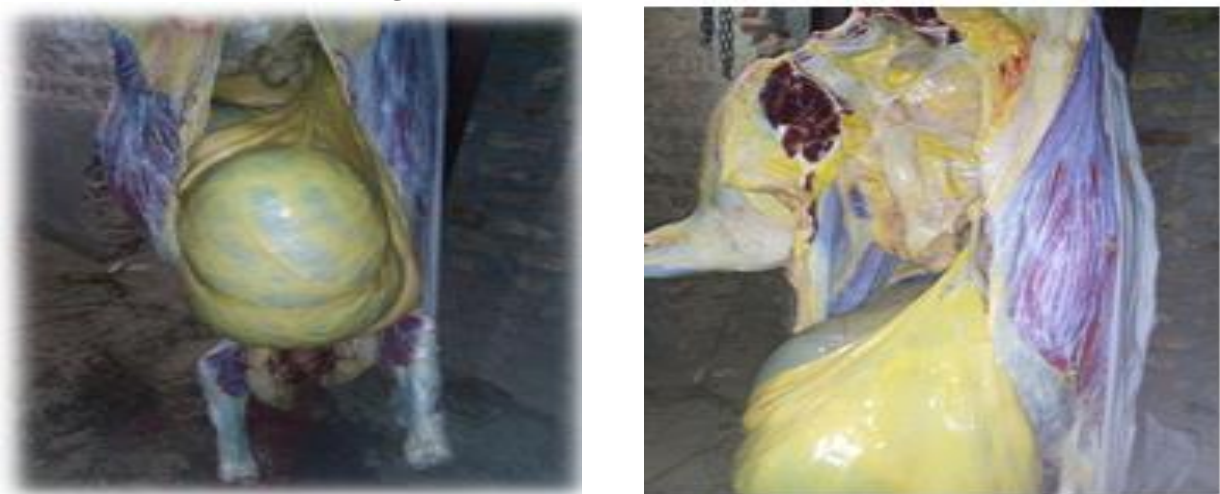

Fig.12: Remarkable wide spread yellowish coloration in the viscera of infected cattle with Theileria infection note: icterus in rumen abdominal viscera and some of internal organ

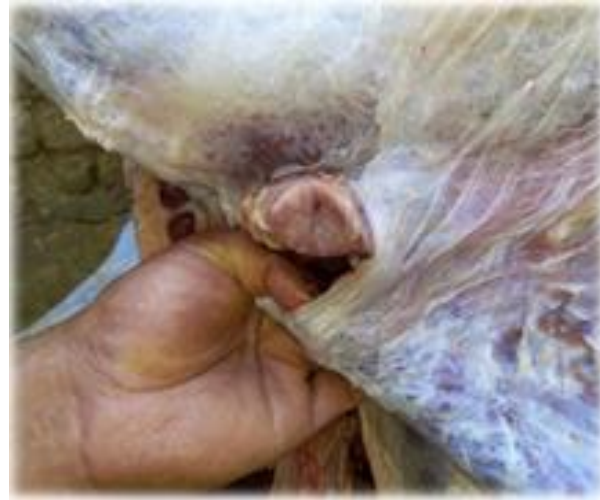

Fig.13: Prescapular lymph node enlargement edematous, hemorrghic

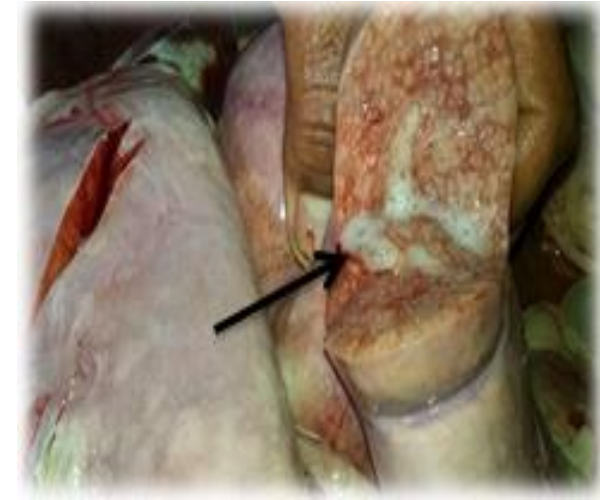

Fig.14: Tenacious fluid (arrow) from lung when palpated or compressed by hand (Lung odema) 


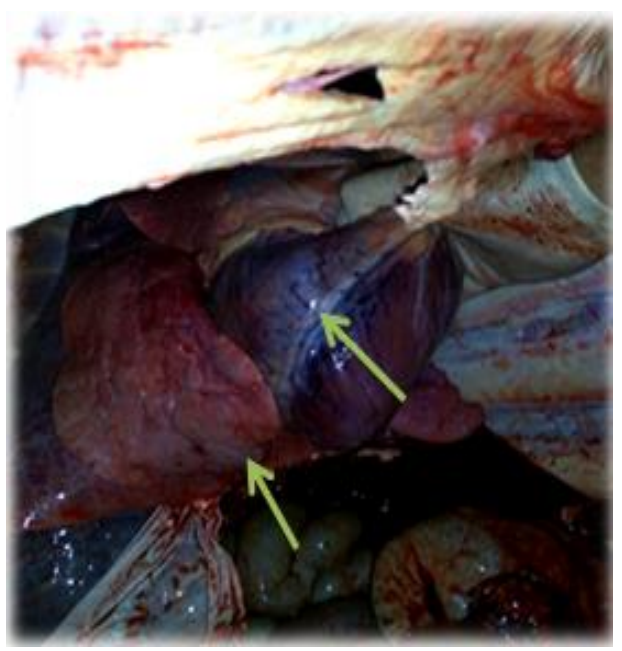

Fig. 15: Remarkable petechiae of heart and extra -edematous swelling of lung (arrow).

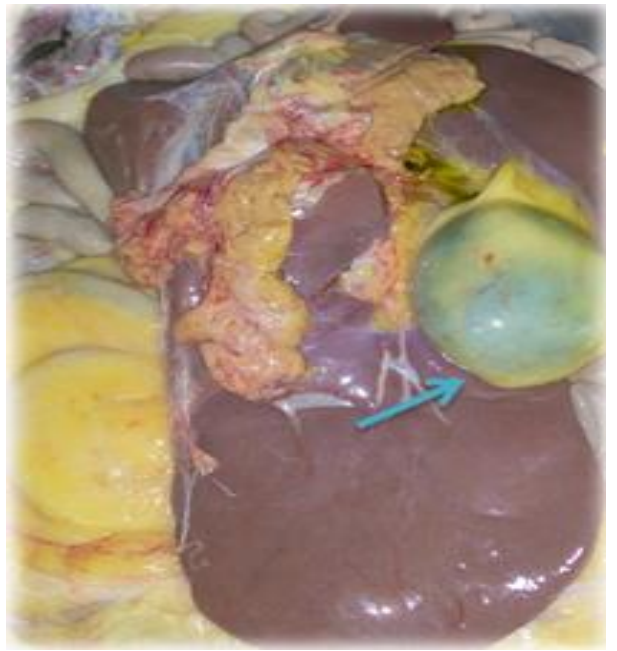

Fig. 16: Obviously distention of gall bladder (arrow) of infected cow with Theileriosis with hepatic enlargement note: falaby icteric liver with icteric fat adjacent to it.

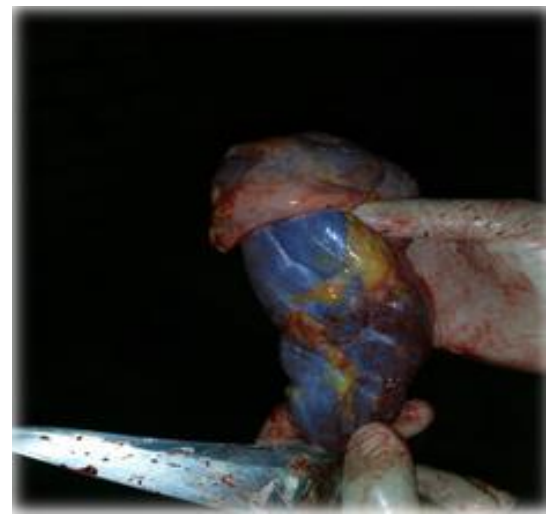

Fig. 17: Kideny edematous with yellowish discoloration of perirenal fat.

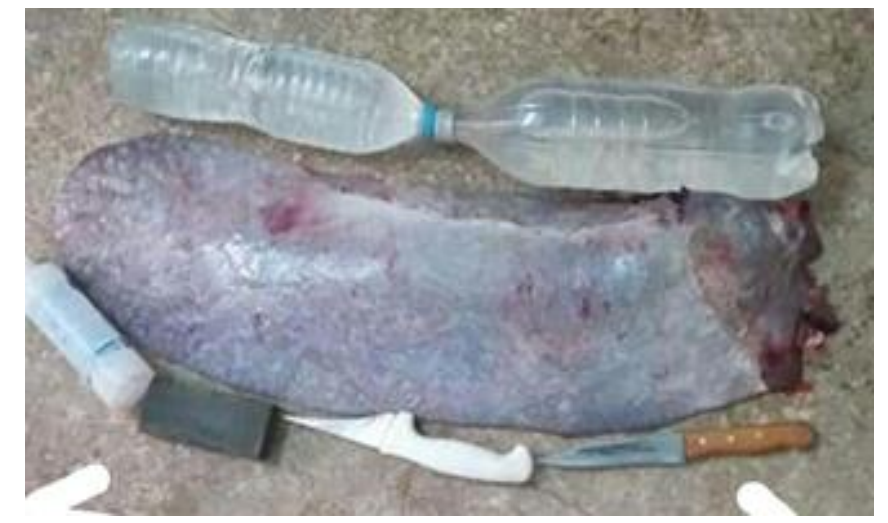

Fig. 18: Splenomegaly of cattle infected with Theileriosis.

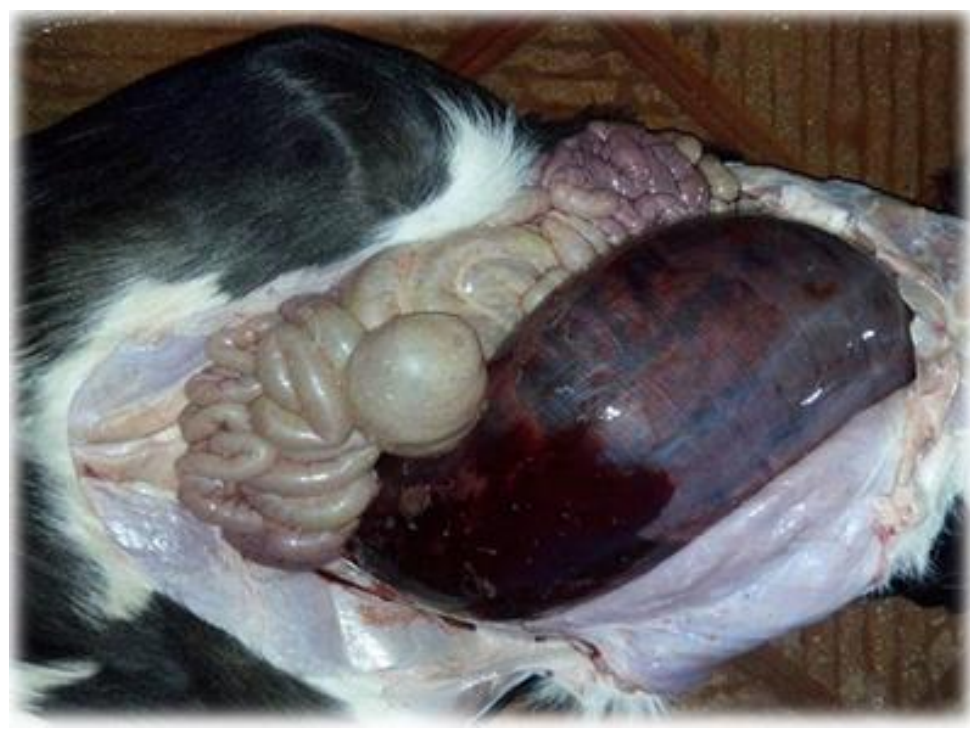

Fig. 19: Highly congested abomasum before opening.(arrow) 

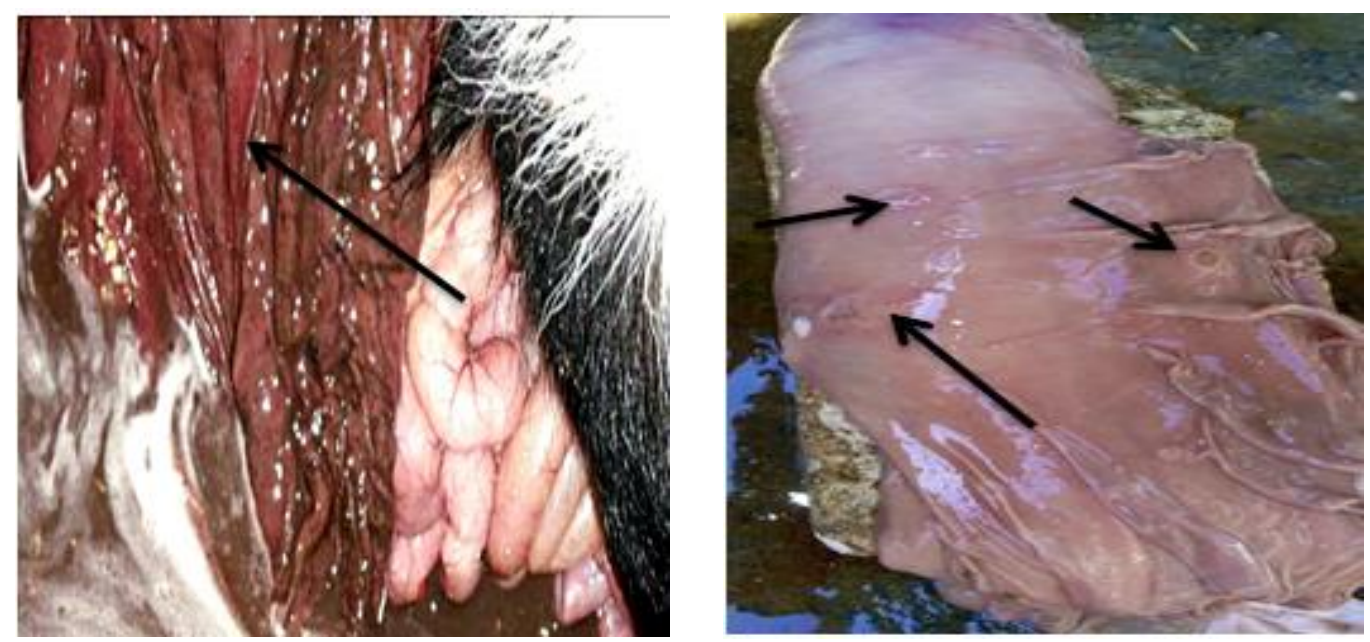

Fig.20 Abomasal ulceration arrows
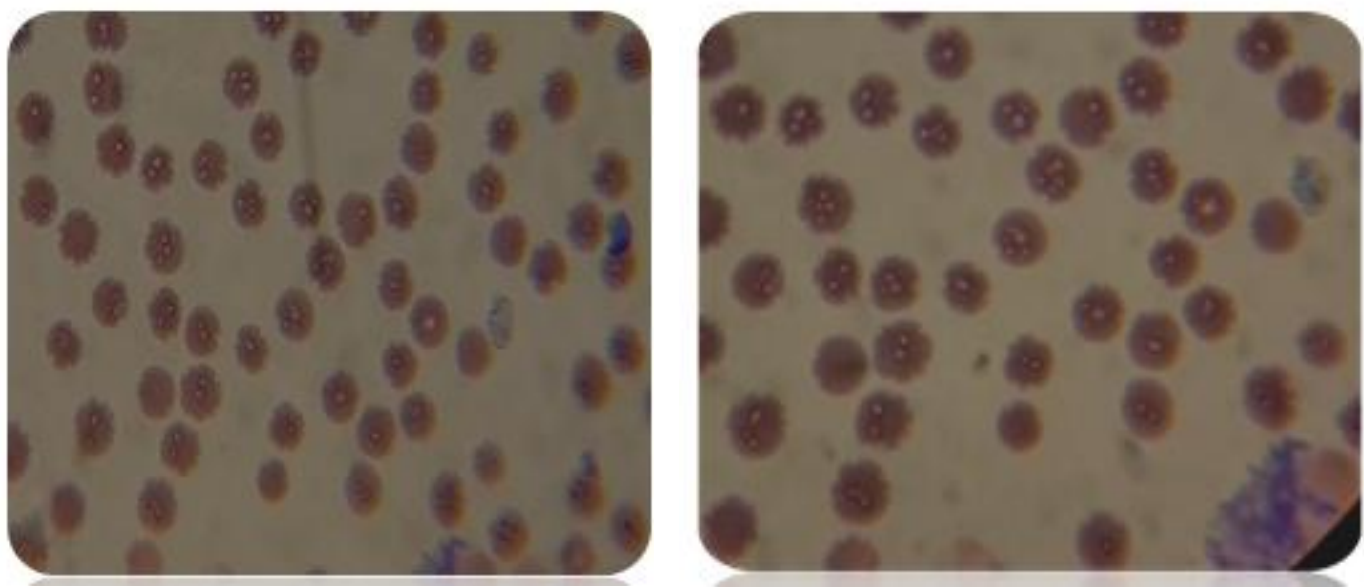

Fig.21: Giemsa stained thin blood film showing the intra-erthrocytic stage of Theileria annulata.x1000
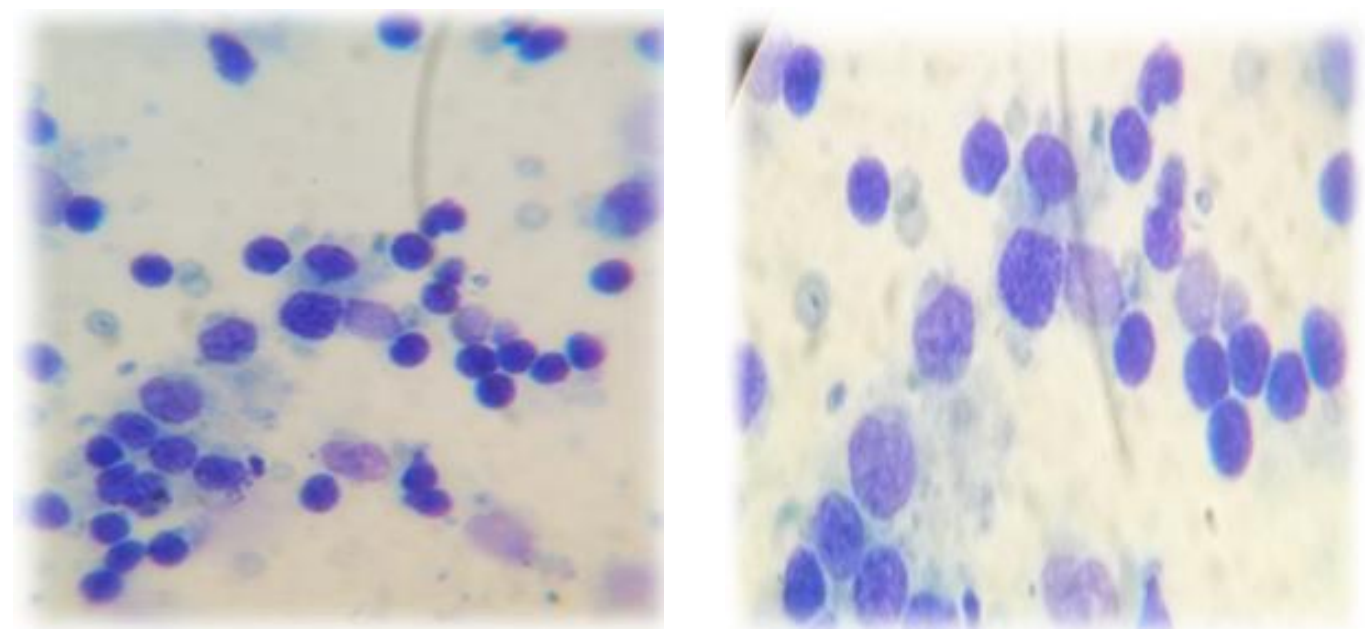

Fig. 22: Lymph smear showing Koch's blue bodies. X 1000 
Theileria Species

\section{A}

Fig.A: Agarose gel (1.8\%) electrophoresis of PCR

amplification products. Lane 1 :

DNA Ladder $100 \mathrm{pb}$.

Lane 2 positive control at $1098 \mathrm{pb}$.

(The black arrow)

Lane 3-8 Positive samples:

Samples 3-5 are cattle's blood

Samples $6-8$ are buffaloes' blood
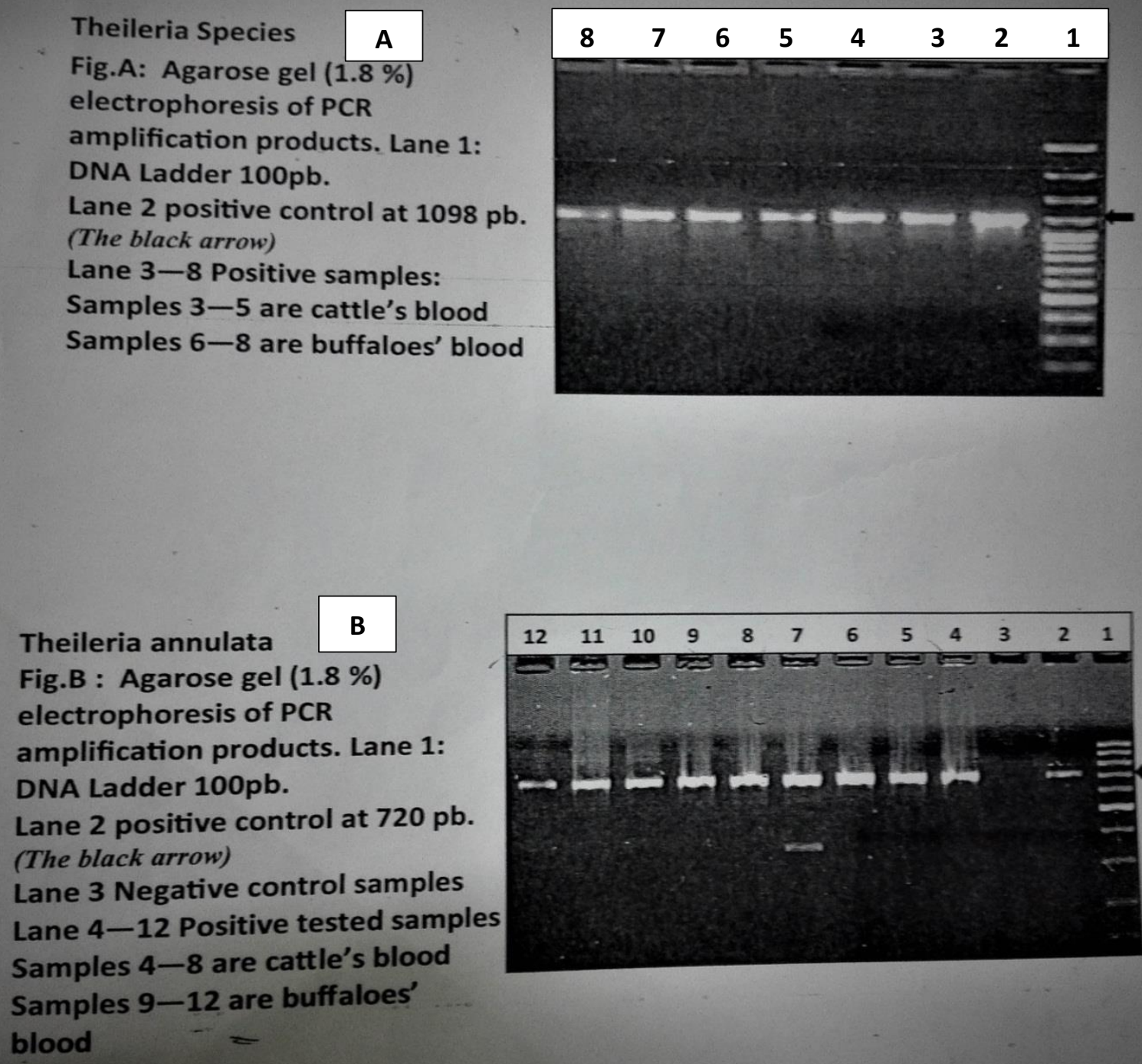

Fig. 23: Agar gel electrophoresis of PCR products of Theileria positive samples DNA extracts with primers specific for Theileria species $A$, and Theileria annulata $B$.

\section{RESULTS}

\section{Parasitological findings}

Total 400 large ruminants (300 cattle and 100 buffalo) with or without clinical signs were screened clinically and parasitologically for theileriosis 95 $(23.75 \%)$ cases of them were found clinically suspected with Theileria parasites.

\section{In case of cattle:}

Out of the clinically inspected cattle $(n=300), 80$ $(26.67 \%)$ were clinically suspected to have Theileriosis. The clinically suspected cases were haematologically (blood film) and lymphomatologically (lymph smear) tested for the presence of Theileria infection.

\section{In case of buffoles:}

A total of 100 boffolas were clinically inspected for Theileriosis, out of them, $15(15 \%)$ were clinically suspected.
Diagnosis (Hematological examination results):

On basis of blood film:

Cattle: A total 300 clinically inspected cattle. Out of them, 80 clinically suspected cattle $26.67 \%$ (80/300) On the basis of blood smear examination (Giemsa stain) 60 cases out of $80(75 \%)$ were showed a Theileria annulata piroplasm. (Fig, 21)

\section{Buffoles:}

A total 100 clinically inspected buffaloes. Out of them, 15 clinically suspected buffaloes $(15 \%)$. On the basis of clinical symptoms and blood smear examination (Giemsa stain) 10 cases out of 15 $(66.67 \%)$ were showed a Theileria annulata piroplasm.

\section{Lymph smear:}

In present study, total 60 animals (cattle) clinically suspected and haematologically positive were found 
positive for Theileria piroplasm 30 animal $50 \%$ (30/60) with lymphadenopathy. Animals were found with enlargement of lymph nodes either unilateral or bilateral enlargement. Out of 30 animals lymph node smears 13 cases with were Theileria schizont positive (43.33\%). (Fig.22). In current study, there is no enlargement of lymph nodes recoreded in bufflaloes.

Specific PCR for examination of $20 \%$ of clinically suspected cases of cattle $(n=16)$ and $50 \%$ of clinically suspected buffaloes $(n=7)$, so large ruminant tested by PCR were 20 samples. Out of 20 tested samples 10 $(50 \%)$ tested by Theileria spp primer and all 20 (100\%) tested by Theileria annulata primer according to D'oliveira et al. (1995) By amplification of Theileria spp. DNA from blood sample were extracted and obtained from both clinically suspected and infected animal and then test by using PCR technique depending on two types of primers as shown in table (1). The first was derived from the gene encoding the SSU $r$ RNA gene used to diagnose Theileria spp. The second primer was derived from the gene encoding the $30-\mathrm{kDa}$ major Theileria annulata merozoite surface antigen according to D'oliveira et al. (1995). The majorty of the molecularly tested samples of large ruminant were Theileria annulata positive. By another meaning out 10 tested samples 6 samples $(60 \%)$ were positive by Theileria spp primer. And out of 20 samples tested by the second primer of Theileria annulata $15(75 \%)$ were positive to Theileria anuulata (Fig.23).

\section{Clinical findings}

In addition to pyrexia and swelling of superficial lymph nodes (Fig., 7,8). Which were used as indicators for clinical disease, inappetance, ocular lesion were white cloudness was more obvious in the centre of cornea rather than the borders (yellowish coloured corneo-scleral opacity surrounded by hypermic zone) (Fig.,1). a watery discharge from the eyes. Serous ocular discharge (watery lacrimation) was remarkable, however in severe cases the ocular discharges was accumulated in the medial canthus (Fig.,1,2,4,5). Some newly born calves of less than one month exposed to ocular symptoms mainly protruding of eye ball with ictric conjunctiva(icteric condition sugessting hepatic insufficiency or coinfection with other hemopathogen like Anaplasma spp,) (Fig.,3). The clinical examination of conjunctivae of the clinically suspected cases with Theilerosis indicated that icteric appearance of conjuntivae in some cases. Some few cases showed petechiated conjunctivae and or vulva (Fig.,9). In our study some animals showed upword visible bulging of temporal fossa (Fig.,6). Another cases showed outword visible protrusion of haemorragic conjunctiva with exopthalmia (ocular oedema) (Fig.,3). Others showed bloody and tarry like diarrhea (Fig.,10). Change in feeding behavior or habit like deprarved appetite by eating mud, soil were observed. Co-infection or concurrent infection with other infectious disease like lumpy skin disease. Tick infestation all over the body also recorded (Fig.,11).

\section{Necropsy findings}

The most prominent features: Gross changes in various organs including heart lungs, trachea, stomach, liver, spleen, kidneys superifial lymph nodes mesenteric lymph nodes, small and large intestine. All mucous membranes and conjunctivae, peritoneum and abdominal fatty tissues were icteric with their intensity varying from case to case. On external observation jaundice, petechial and ecchymotic haemorrhages involving mucosal and serosal surfaces of many organs as well as body fat. In the thoracic cavity, the most prominent autopsy findings were obviously extra edematous swelling of all lobes of the lung, hydrothrox and the lung were distended, discolored, solid in texture, and filled with exudate by palpation (Fig.,14). The liver was friable, yellowish, and larger than normal, with the gall bladder being markedly distended with dark olivegreen or brownish green bile (Fig.,16). The abomasum was the most severely affected organ in the alimentary canal, it contains numerous ulcers about $3 \mathrm{~mm}$. in diameter a few linear ulcers were present on the leaves. There were prominent hemorrhagic ulcers and petechiae seen in abomasum in most of cases (Fig.,20). There were remarkable enlargement of spleen recorded (Fig.,18,19). The kidneys were pale, congested or dark brown in color and their perirenal fat were yellowish in color (Fig.,17). The heart had petechial and eccymotic haemorrhages on the outer and inner surface of the auricles. (Fig.,15).

\section{DISCUSSION}

Tick-borne diseases hamper the progression of the livestock industry and Theileriosis is, unfortunately, an endemic disease among cattle and buffalo population in our country (Mason, 1922 and Daubney and said., 1951). At the beginning of the last century, since 1922 Mason gave a loud-shout about the importance of the disease. The settlement of Theileria infection may due to the continuously existence of the ticks responsible for life-saving and transmission of Theileria infection from invertebrate to vertebrate hosts, without strategic program of eradication, which is the cornerstone in preventive measures of Theileriosis.

T. annulata infection in this study was diagnosed by observing the intraerythrocytic forms (Fig.,21). Koch's blue bodies in the lymphocytes of the lymph nodes (Fig.,22), and Molecular examination revealed that these animals were infected with $\mathrm{T}$. annulata.

The clinical signs and the pathological changes reported in the present wrok in cattle and buffaloes were similar to previous studies (Gill et al., 1977; Uilenberg 1981; Omer et al., 2002). In almost of the 
animals (six animals) necropsied, the gross lesions was similar to work of Panda et al. (2011) and Mahajan et al. (2013).

The necropsy lesions including hepatomegaly, splenomegaly, and abomasal ulcers are in agreement with those reported by Sandhu (1996), Oryan et al. (2012), Sandhu (1996) who indicated severe damages to the hepatobiliary system due to hypoxia that resulted from hemolytic anemia and jaundice. The gross pathological lesion in infected animals were represented by general emaciation and other or some cases of icteric skeletal muscles, abomasal ulcers, the necrotic foci in differcnt organs Some investigators claimed the immunomorphological changes Fedorov and Karput (1970) due to a toxin excreted by the potozoan it sclf Hooshinand Rad (1976), enlargement of body lymph node specially superficial lymph node were enlarged with edema and congestion, liver was enlarged, flabby and pale yellow in colour with gall bladder fully distended by bile juice, enlargement of spleen punched out haemorrhagic ulcers in large numbers. The small intestine was markedly distended with congestion. Abomasal ulcer is of diagnostic significance for Theileriosis which was consistently evident in all the cases, These ulcers were also varying in sIze and color, probably due to the formation of petechiae that causes ischemia or anemia (anoxemia) locally resulting in the death of tissues in this foci, or due to the digestion of local epithclial cells affected by excreted enzymes from the present glands. The necrotic epithelium then was exfoliated by the friction of the content into the stomach lumen to leave an ulcer behind. These ulcers were surrounded by a hyperemic, intensely edematous and inflammed zone due to the secondary infections by the present flora or by other agents might come. (Dschunkowsky and Luhs, 1904). The heart showed redness (hemorrhage on pericardium) the animals showed congestion and edema of the lungs particularly the diaphragmatic lobes. There were frothy exudates in the trachea and bronchi. Lung edema may be explained due to effect of disturbance in fibrin and fibrinogen level in blood (Shitakha et al., 1983). Another opinion explains the results of lung edema due to releasing of the serotonin substance produced from massive destruction of platelets act as vascular dilator which leads to increasing the perimiabalty and producing edema (Kimeto, 1978) the myocardium was comparatively enlarged and congested Kidneys showed enlargement Perirenal fat was slightly icteric. The pathological changes reported in the present investigation were similar to those described for $\mathrm{T}$. annulata infections in the previous studies More or less similar gross findings were described by various workers Sivaseelan (2003), Ahmad et al. (2007), Panda et al. (2011) and Mahajan et al. (2013).

\section{PREFERENCES}

Ahmad, A.; Ahmad, M. and Ahmad, R. (2007): Studies on the occurrence, clinical features and clinicopathological aspects of theileriosis in buffaloes, Italian Journal Animal Science, 6(2): 932-934.

Bilgic, HB.; Karagenc, T.; Bakırcl, S.; Shiels, B.; Tait, A. and Kinnaird, J. (2016): Identification and analysis of immunodominant antigens for ELISA-based detection of Theileria annulata. PLoS-ONE,11(6):e0156645. https://doi.org/10. 1371/journal.pone.0156645.

Chaudhri, S.S. and Gupta, S.K. (2003): Manual of General Veterinary Parasitology. 1st edition. department of Vet. Parasitology College of Vet. Sci. Haryana Agicultural University India.Pp:46-47.

D'Oliveira, C.; Van-der Weide, M.; Habela, A.; Jacquiet, P. and Jongejan, F. (1995): Detection of Theileria annulata in blood samples of carrier cattle by PCR. J Clin Microbiol 33(10): 2665-2669.

Daubney, R. and Said, M.S. (1951): Egyptian fever of cattle The transmission of Theileria annulata ((DZCHUNKOWSKY and LUHZ 1904) by Hyalomma exacavatm KOCH, 1844 Parasitology, 41(3-4), 249. 260 doi: 10.1017/ s0031182000084079.

De-Castro, J.J. (1997): Sustainable tick and tickborne disease control in livestock improvement in developing countries. Vet. Parasitol. 71: 77-97.

Dolan, T.T. (1986): Chemotherapy of east coast fever: The long term weight changes, carrier state and disease mani- festations of parvaquone treated cattle. J. Comp. Pathol., 96: 137.

Dschunkowsky and Luhs (1904): Die piroplasmen der rinder. Central Bakteriolo Parasiten Infektion. 35: 486-492.

Fedorov, A.L. and Karput, I.M. (1970): Immunomorphological changes in the hematopoietic organs of cattle with Babesia and Theileria annulata infections., Uehen.Zap. Vitebsk. Vet.lnst., 22: 67-72j

Flach, E.J. and Ouhelli, H. (1992): The epidemiology of tropical theileriosis (Theileria annulata infection of cattle) in an endemic area of Morocco. Vet. Parasitol., 44: 51-65.

Gharbi, K.; Souidi, M.A.; Boussaadoun, A.; Rejeb, S.; Jabloun, A. Gnaoui and Darghouth, M.A. (2017): Dermatological signs in bovine tropical theileriosis (Theileria annulata infection), a review Rev. Sci. Tech. Off. Int. Epiz., 2017, 36 (3), 807-816.

Gharbi, M. and Darghouth, M.A. (2015): Control of tropical theileriosis(Theileria annulata infection in cattle) in North Africa. Asian Pac. J. Trop. Dis., 5 (7): 505-510, doi: $10.1016 /$ S2222-1808(15)60825-8. 
Gill, B.S.; Bhattacharyulu, Y. and Kaur, D. (1977): Symptoms and pathology of experimental bovine tropical theileriosis (Theileria annulata infection). Annales de Parasitologie 52, 597608.

Hooshinand Rad, P. (1976): The pathogenesis of anemia in Theileria an1udata i1yection., Res. in VeLSci.20: :124-329.

Ilhan, T.; Williamson, S.; Kirvar, E.; Shiels, B. and Brown, C.G.D. (1998): Theileria annulata: carrier state and immunity. Ann. N.Y. Acad. Sci., 849: 109-125, doi: 10.1111/j.1749-6632. 1998.tb11040.

Jackson Peter, G.G. and Peter D. Cockcroft (2002): Clinical examination of farm animals.

Jubb, KVF, Kennedy, PC. and Palmer, N. (1993): Pathology of Domestic Animals. Academic Press; 4 edition. ISBN-13: 978-992.

Kelly, WR. (1979): Veterinary clinical diagnosis $2^{\text {nd }}$ Edn., Bailliere Tindall, Lonon, Pp: 261-300.

Kimeto, B.A. (1978): Ultrastructure of blood platelets in cattle with East Coast Fever. J. Amer. Vet. Res. Vol. 37 No. 4., 445-447.

Kivaria, F.M.; Ruheta, M.R.; Mkonyi, P.A. and Malamsha, P.C. (2007): Epidemiological aspects and economic impact of bovine theileriosis and its control: A preliminary assessment with special reference to Kibaha district, Tanzania. The Veterinary Journal 173: 384-390.

Kundave, V.R.; Hira Ram; Shafiya Imtiaz Rafiqi; Rajat Garg; Ashok Kumar Tiwari and Banerjee P.S. (2017): Comparative Evaluation of Microscopy and PCR Assay for Detection of Theileria annulata Infection in Ruminants Journal of Animal Research: v.7 n.4, p. 699703 .

Mahajan, V.; Gupta, M.P.; Bal, M.S.; Kumar, H.; Mittal, D.; Filia, G.; Sharma, S.; Banga, H.S.; Verma, S.; Kaur, K.; Vasudev, A.; Singla, LD. and Sandhu, KS. (2013): Outbreaks of Theileriosis in Cattle in Punjab. Indian Veterinary Journal, 90(1): 77-78.

Mason, F.E. (1922): Egyptian Fever in Cattle \& Buffaloes. Journal of Comparative Pathology and Therapeutics, 35, 33-39. cited by doi:10.1016/s0368-1742(22)80003-5.

Mehlhorn, H.; Schein, E. and Ahmed, J.S. (1994): Theileria. In: Kreier, J.P. (ed.), Parasitic Protozoa, Volume 7. pp. 270-271. Academic Press, Inc., New York, USA.

Neitz, W.O. (1959): Theileriosis. Adv. Vet. Sci., 5: 241-297.

OIE (2014, seventh ed.): Manual of Diagnostic Tests and Vaccines for Terrestrial Animals, vol. 1-2, Office International Des Epizooties, Paris (2014).

Omer, OH.; El-Malik, KH.; Mahmoud, OM.; Haroun, EM.; Hawas, A.; Sweeney, D. and Magzoub,
M. (2002): Hematological profiles in pure bred cattle naturally infected with Theileria annulata in Saudi Arabia. Vet Parasitol 107: $161-168$.

Oryan, A.; Fatemeh Namazi; Hassan Sharifiyazdi; Mostafa Razavi and Reza Shahriari (2012): Clinicopathological findings of a natural outbreak of Theileria annulata in cattle: an emerging disease in southern Iran. Volume 112, Issue 1, pp 123-127.

Panda, SK.; Sahu, B.; Rajeev Ranjan; Acharya, AP. and Rath, SK. (2011): Prevalence and clinicopathological study of theileriosis in bovine in coastal areas of Orissa. Indian Journal Veterinary Pathology.; 35(2):128-132.

Roy, KC.; Ray, D.; Bansal, GC. and Singh, RK. (2000): Detection of Theileria annulata carrier cattle by PCR, India Journal of Experimental Biology, 38: 283-284.

Sahoo, N.; Bikash Kumar Behera; Hemant Kumar Khuntia, and Manojita Dash (2017): Prevalence of carrier state theileriosis in lactating cows Vet World. 2017 Dec; 10(12): 1471-1474.

Sandhu, GS. (1996): Histopathological, biochemical and hematological studies in crossbred calves suffering from experimental tropical theileriosis. MVSc Thesis, Punjab Agricultural University, Ludhiana.

Shitakha, VM.; Natulya, VM.; Musoke, AJ. and Basher, G. (1983): Complemint activety and fibrolysis during infection with Theileria parva. Vet. Immun. and Immunopath. 4.(3): 361-373.

Sivaseelan, S. (2003): Combined infection of babesiosis and theileriosis in crossbred dairy cow: A postmortem report, Indian Veterinary Journal, 80(6):572-573.

Tuli, A.; Singla, LD.; Sharma, A.; Bal, MS.; Filia, G. and Kaur, P. (2015): Molecular epidemiology, risk factors and hematochemical alterations induced by Theileria annulata in bovines of Punjab (India) Acta Parasitol. 2015; 60:378390. doi: 10.1515/ap-0053.

Uilenberg, G. (1981): Theilerial species of domestic livestock. In: Irvin AD, Cunningham MP, Young AS (eds) Advances in the control of theileriosis. Martinus Nijhoff, The Hague, pp4-37

Uilenberg, G. (2004): Diagnostic microscopique des maladies transmises par les tiques au Maghreb. Arch. Inst. Pasteur Tunis, 81 (1-4): 35-40.

Van-Amstel, R.S. (1982): Bovine cerebral theileriosis .some aspects on its clinical diagnosis .proc. XIIth World Cogress on Diseases of cattle. Vol.II. The Neitherland world Association for Buiatrics. Amsterdam.pp:981-985. 


\title{
دراسة اكلينيكية وتثريحية عن مرض الثيلريا الحلقية فى الابقار والجاموس بمنطقة الغتايم ـ
}

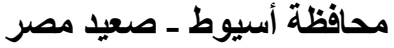

\section{أحد محمود عطية زيتون ، أحمد عبل الراضم محمود ، أمبيزة عادل طه الحصرى ، مايكل ريوف عزيز مكسبيوس}

E-mail: michealraoof@yahoo.com Assiut University web-site: www.aun.edu.eg

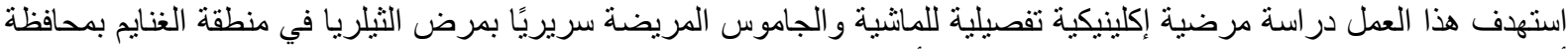

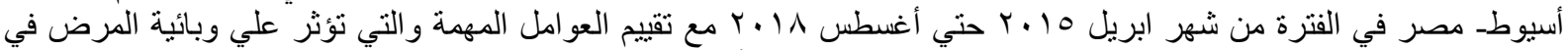

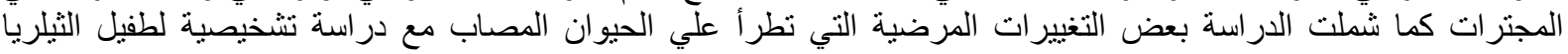

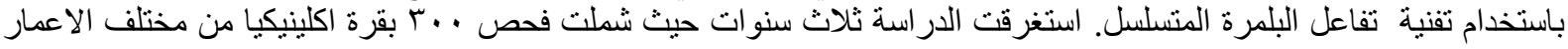

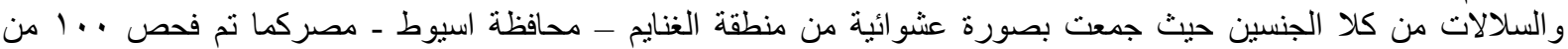

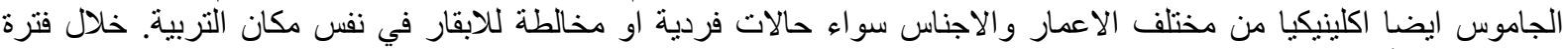

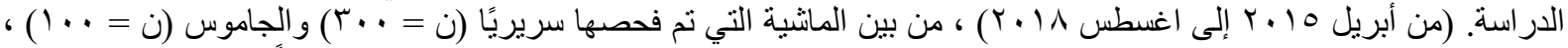

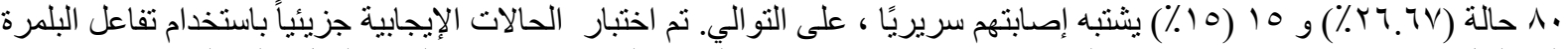

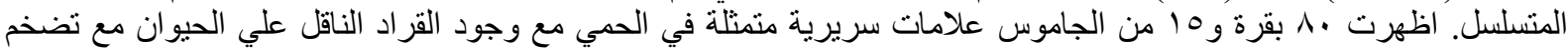

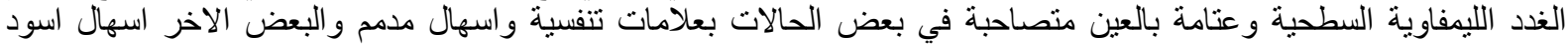

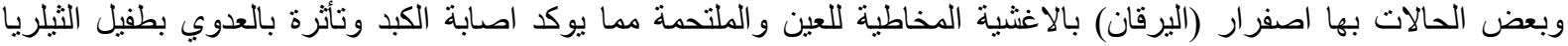

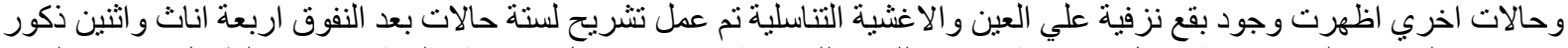

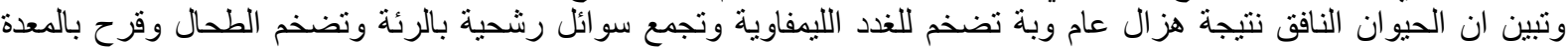

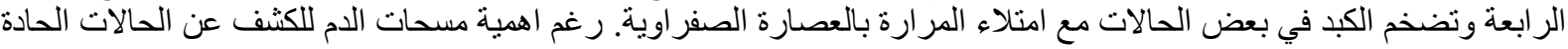

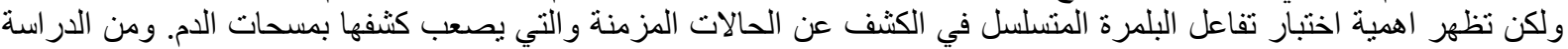

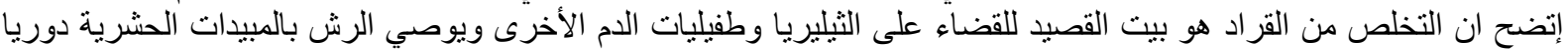

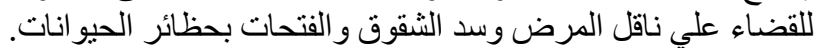

